\title{
INTERNATIONAL RED CROSS ASSISTANCE IN INDO-CHINA
}

International Red Cross Assistance for Indo-China is expanding its activities to the full extent that financial and material support provided by Governments and National Societies makes possible.

\section{Democratic Republic of Vietnam}

The programme for emergency prefabricated housing in Hanoi and Haiphong is now gathering momentum. The group of experts has virtually completed its task of examining tenders from a number of countries and companies, based on the detailed specifications drawn up in consultation with the Red Cross of the Democratic Republic of Vietnam. Several large orders have been placed and options arranged for others as and when funds become available. Preparations for sites and the provision of infrastructure material are also proceeding well.

\section{Republic of Vietnam}

The teams of the Indo-China Operational Group (IOG) are continuing their activities. On 15 September, a medical team provided by the Netherlands Red Cross started work in the Chaudoc area. The team, which is composed of a doctor and two nurses, will concentrate mainly on the care of Cambodian refugees in various camps. Two French doctors in the Plei Mnang area provide treatment for the Vietnamese montagnard population.

\section{Provisional Revolutionary Government of the Republic of South Vietnam}

Medical expert groups from the IOG and the Provisional Revolutionary Government of the Republic of South Vietnam met in Hanoi in August for discussions concerning the equipment of a 250-bed hospital. It was decided that the hospital would be a fixed regional general hospital also serving as a medical college hospital with training facilities for graduates and post-graduates. 


\section{IN THE Red Cross World}

\section{Khmer Republic}

In addition to the heavy workload at the Kantha Bopha children's hospital, the paediatric team of the Swiss Red Cross is also providing basic medical care in several camps for displaced persons in Phnom Penh. A new surgical team made available by the Belgian Red Cross is at work at Svay Rieng. At the time of writing, a joint Danish-Norwegian team is being assembled for work in Kampong Thom. The Swedish Red Cross has already formed a surgical team to be stationed in Phnom Penh and available for immediate short-term operations in areas which suffer from the fluctuating war in the country.

\section{Laos}

The French Red Cross team is working in rural areas along the Mekong river south-east of Paksane. The British team is also at work in the Paksane hospital and in that town's surroundings. In August, it provided treatment for more than 1,650 patients. In some fifteen villages in Pak Lay, the Japanese team has launched a vaccination campaign for more than 2,600 persons. The Swiss medical team has also concentrated on a vaccination campaign for the Meo people of the mountains south of Luang Prabang; during the week from 20 to 25 September, more than 4,000 persons were immunized.

\section{Pathet Lao}

Medicaments are sent weekly by air from Vientiane to Sam Neua for the population of areas under Pathet Lao control. 


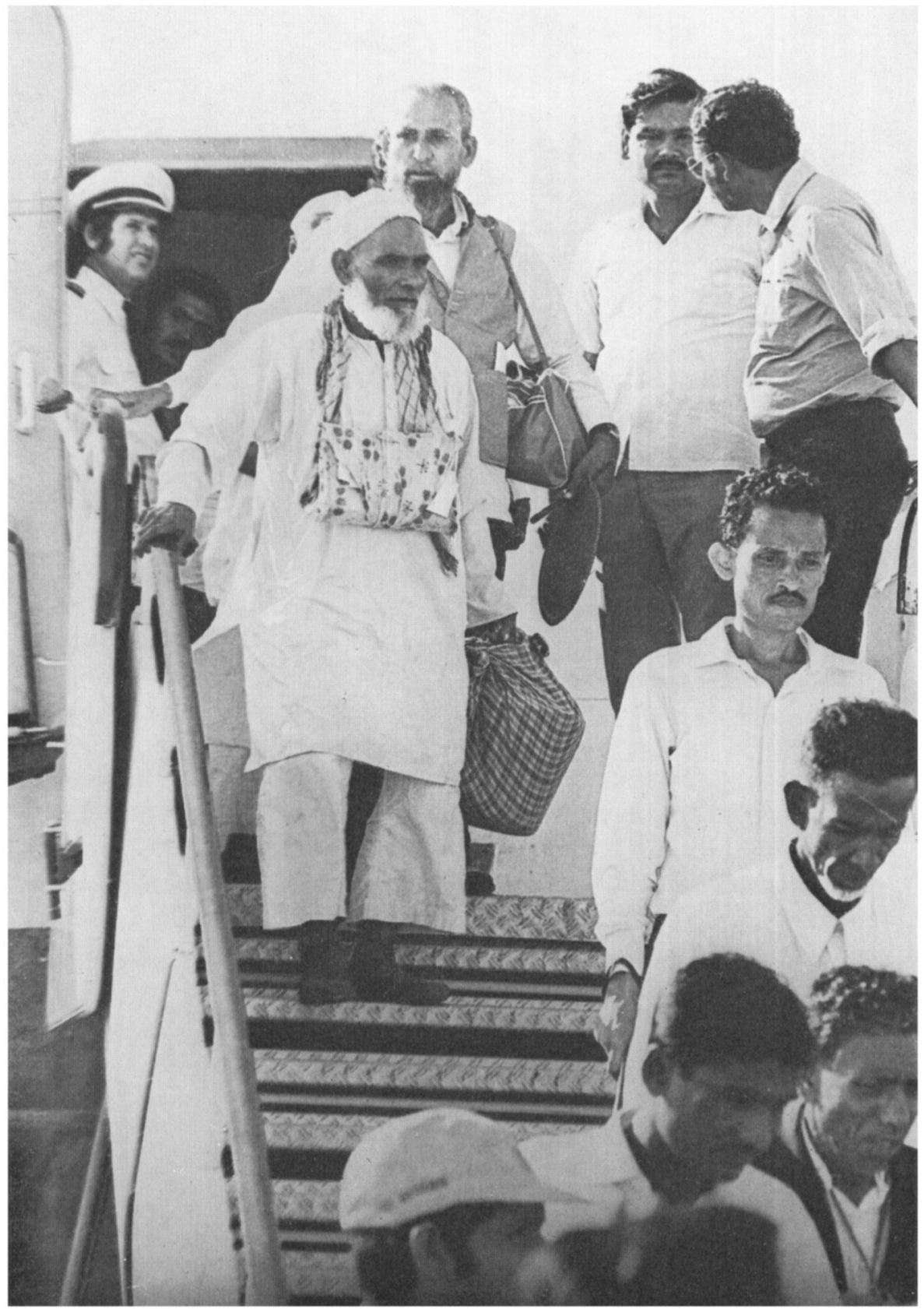

Arrival in Dacca of first group of Bengalis repatriated from Pakistan under ICRC auspices. 


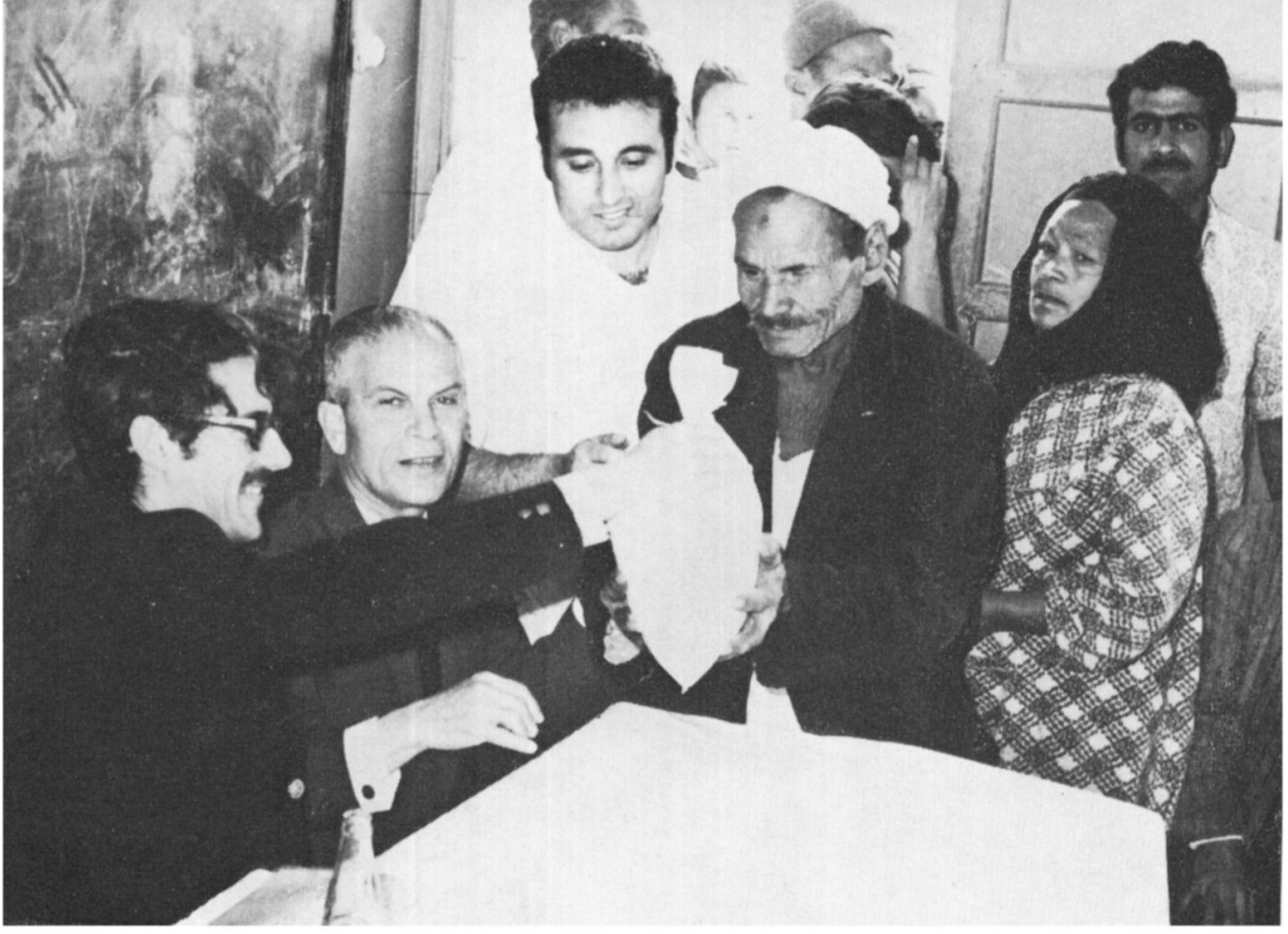

Cairo: Distribution of relief supplies to displaced persons by the Egyptian Red Crescent and ICRC (July 1973).

Rangoon: ICRC regional delegate in South East Asia (left) received by members of the Executive Committee of the Burma Red Cross.

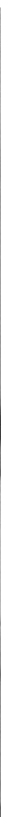

